\title{
Mobile Payment and Mobile Application (App) Behavior for Online Recommendations
}

\author{
Shu-Hsien Liao, Tamkang University, New Taipei City, Republic of China \\ Chu-Hung Ho, Tamkang University, New Taipei City, Republic of China
}

\begin{abstract}
A mobile application (app) is an application designed to run on a smartphone, tablet, or other mobile device. With the continuous change of mobile payment applications in smart phones and the support of the banking system, the global mobile payment population is increasing. This study examines the behaviors of Taiwan mobile payment and app users, using a total of 1,176 valid questionnaire responses divided into six sections with 29 items for a database design. This study develops a data mining approach, including clustering analysis and association rules, based on a relational database. Thus, this study shows that mobile payment not only can provide payment service but also be a critical mobile application platform for online business. Finally, the authors show that as users of mobile payment and apps gain additional demand and consumption ability, online operators can gradually put together mobile payment business models to enable future electronic commerce online recommendations.
\end{abstract}

\section{KEYWORDS}

Data Mining, Electronic Commerce, Mobile Applications (Apps), Mobile Payment, Online Recommendations

\section{INTRODUCTION}

With the continuous change of mobile payment applications by smart phone coordinated with banking systems, the global mobile payment population is increasing (Cao et al., 2018). According to eMarketer research tracking and estimation, $34.9 \%$ of retail payments were made by mobile phone in 2018 (Dolliver, 2018). Currently, Apple Payments, Google's Android Payments and Samsung Payments are expanding their international payment range in different ways. In the world's largest mobile payment market, China, under the leadership of Ali Pay and WeChat payment, payment consciousness and life modes of Chinese people have changed dramatically (Euromonitor International Market Report, 2019). In regional markets, China is a global leader in near-end mobile payment applications, accounting for $61.2 \%$ of global mobile payment users in 2018. Even as China's market share declines with more users in other parts of the world, China will still account for $56.0 \%$ of the global users of near-end mobile payments in 2022. China's penetration rate of near-end mobile payment users in the Asia-Pacific region will be as high as 50\%. However, from the perspective of total population use, the Asia-Pacific region is comparable to North America. In North America the use of smart phones came earlier, so North American users are more willing to try to mobile payment (Sonawane, 2018). In parts of Western Europe, the use of contactless cards for payment by consumers has restricted the development of near-end mobile payments. Since Western Europe introduced a contactless payment service using

DOI: 10.4018/JOEUC.20211101.oa2

This article published as an Open Access article distributed under the terms of the Creative Commons Attribution License (http://creativecommons.org/licenses/by/4.0/) which permits unrestricted use, distribution, and production in any medium, provided the author of the original work and original publication source are properly credited. 
credit and debit cards, consumers feel that it is unnecessary to make payments via mobile phones. But if operators can develop a differentiated service model, businesses can change the current market situation (Techcrunch Newsletters, 2019). In emerging markets such as Latin America, the Middle East and Africa, the biggest obstacles to the use of near-end mobile payments include low bank account penetration, low penetration of smartphones, and lack of support for payment terminals. Instead of using advanced technology payment services, other methods such as non-contact stickers are favored. Overall, eMarketer reported that $13.2 \%$ of the world's population used near-end mobile payments in 2018. By 2021, this proportion is expected to grow to $17.2 \%$. While the growth rate of this forecast may disappoint manufacturers, it does illustrate the potential for strong growth (eMarketer, 2019).

In the Taiwan mobile payment market, according to the results of the MIC survey. the Taiwan Council, the top five areas of rapid mobile payment development between 2017 and 2018 included, "convenience stores (75.6\%)," "volume shops (42.5\%)," "supermarkets (40.1\%)," "department/ shopping centers (36.4\%)" and "chain catering (33.3\%)". Of these, the growth of convenience stores was the fastest, with a $13.3 \%$ increase from 2017 to 2018 . In addition, five fields with high potential for expansion in 2018 included "Internet stores (36.2\%)", "chain stores (22.8\%)", "transportation (22.3\%)", "payments (17.2\%)", along with other services, such as virtual goods services, such as maps, in-app consumption, virtual treasures, etc. "(11.8\%)", showed high growth potential. Moreover, the online store penetration rate increased by $16.4 \%$ over 2017 . Transportation grew by $8.4 \%$. Taiwan's mobile payment penetration rate in 2018 reached 50.3\%, a significant increase from $39.7 \%$ in 2017 (Taiwan MIC, 2019). In 2018, one out of every two people between the ages of 18 and 65 who had smart mobile apps used mobile payments in 2018. Further observation changing age of users reveals that mobile payment action clearly increased in students, recent graduates and seniors in 2018 . The penetration rate of mobile payment app users aged 18 to 25 increased greatly, from $39.2 \%$ in 2017 to $63.3 \%$ in 2018 , while the penetration rate of mobile payment users aged 56 to 65 increased from $26.3 \%$ to $41.4 \%$. From the perspective of overall age, the penetration rate of mobile payment users aged 26-55 exceeded 40\% in 2017, and the penetration rate of mobile payment users aged 26-35 in different age groups was 50\%. However, the penetration rate of mobile payment users of all ages in 2018 reached more than $40 \%$, and the penetration rate of young adults aged 18 to 45 exceeded $60 \%$ (Money Magazine, 2019). According to the Taiwan Semiconductor Research Institute, the top three most commonly used mobile payment apps for Taiwanese people in 2018 were LINE Pay (25.2\%), Apple Pay (17.9\%), and JKO Pay (10.4\%). Of these, Apple Pay actually only binds credit cards and does not provide supplemental services, limiting its potential for growth. Therefore, future expansion may lie in a connection between LINE Pay and JKO Pay (Taiwan TSRI, 2019).

Currently, offline payment points are accepted by 50,000 merchants and the number of users has exceeded 2.6 million. JKO Pay uses a localization strategy since its capital is much less than that of LINE. Therefore, with the strategy of "village surrounding the city", JKO Pay started with night market vendors, and then moved into physical stores such as beverage stores. LINE Pay and JKO Pay together currently have more than 4.1 million users in Taiwan, and about a dozen banks can directly connect to these accounts (Huang, 2019).

This study examines experiences of Taiwan users to understand aspects of mobile payment apps and contribute to business model development. It also looks at how the situations of mobile payment app proprietors and their affiliates are disseminated through mobile payment app online recommendations.

\section{LITERATURE REVIEW}

\section{Mobile Payment}

Mobile payment lets consumers pay for goods or services they purchase through mobile devices (usually smart phones or tablets). Consumers send payment instructions directly or indirectly to 
banks and financial companies via mobile devices, the Internet, or proximity sensing (near-field communication, NFC) to generate monetary payments and fund transfers. By facilitating mobile payments for funds and enabling terminal devices, application providers and finance firms can complete financial services via the Internet (Gerpott \& Meinert, 2017). Mobile payments can also be made using credit cards, membership cards, transportation tickets, etc., to a mobile terminal, thus transforming the mobile phone into an electronic wallet (Wang et al., 2019). With advancements in technology, mobile terminals offer excellent mobility and provide specific services. This can free consumers from travel to designated locations to handle business, and eliminates geographical restrictions of business locations (Pauluzzo \& Geretto, 2018). The interaction between a mobile communication terminal and the Internet platform has replaced traditional manual operations, so mobile payments are no longer limited by the business hours of the relevant financial enterprises and businesses, and 24-hour uninterrupted financial service is realized. On the other hand, mobile payments are accurate, with no need to pay change, speed, multi-functionality, all-weather service, and unsecured outlets. In regard to the payment method, micro-payment refers to payments of small funds on the Internet (Huang, 2017). This kind of mobile payment mechanism has special system requirements. Under the premise of satisfying certain security requirements, less information transmission is required, and lower management and storage requirements are needed for network speed and efficiency (Du, 2018). Micropayment refers to transaction amounts of less than 10 US dollars, and usually involves purchases of mobile content services, such as games, video downloads and so on. Macro-payment (also known as regular payment) is another mobile payment mechanism. The transaction amounts are generally large, at least a few dozen US dollars (Yen et al., 2014). In order to ensure security, the protocol format and steps of transactions are more complicated, and a large number of public key technologies are adopted. The difference between the two payment methods is the level of security requirements. For example, for macro payment methods, it is necessary to conduct transaction authentication through a reliable financial institution; for micropayments, it is sufficient to use the SIM card authentication mechanism of the mobile network itself (Fan et al., 2018).

\section{Mobile Applications (Apps)}

A mobile application (app) is an application designed to run on a smartphone, tablet, or other mobile devices. Mobile device users can download mobile software applications for free or for a fee via wireless networks from mobile software apps stores (Son, 2017; Goldbach et al., 2018). In addition to browsing and trading through a web browser such as a general online store, mobile software app stores usually also have dedicated apps that allow users to enter with one click and the interfaces of these stores are more convenient than web pages (Fang, 2019). The first mobile payment apps operator to adopt this business model was the "App Store" operated by Apple Computer Inc. for its mobile devices, the iPhone and iPad. Google also launched its own app store, Google Play, along with its mobile operating system Android. Thus, mobile payment apps such as Google Wallet, Apple pay, Samsung Pay, and so on, are generating a new trend not only in technological development but also in market business model innovation. Thus, the integration of apps with mobile payment has developed into a business model that features co-operation among finance, communication, ICT technology and retailing operators based on finance technology (FinTech) development (Choi \& Lee, 2018; Karim et al., 2020).

\section{Data Mining}

In regard to investigate mobile payment Apps users' behavior, the data mining approach, which means using a large database to build a model and find hidden special associations and features, is the process of discovering patterns in a relatively large data set using the intersection of artificial intelligence, machine learning, statistics, and databases (Bauer \& Jannach, 2018; Khatwani \& Srivastava, 2018; Kühl et al., 2019; Shahri et al., 2019). Many data mining models have been proposed such as classification, estimation, predictive modeling, clustering/segmentation, affinity grouping 
or association rules, description and visualization, as well as sequential modeling. Similarly, many application methods, including association rules, sequential patterns, grouping analysis, classification analysis and probability heuristic analysis have been used in the research of online marketing (Chen et al., 2014; Pant \& Pant, 2018; Sung et al., 2020). Knowledge of mobile payment Apps users extracted through data mining can be obtained through electronic commerce and online recommendations research and then provided to mobile payment businesses, thereby serving as a valuable reference for building their possible business and profit models (Buettner, 2017; Khan et al., 2019).

\section{Personalized Recommendation Systems (PRS)}

Personalized recommendation systems (PRS) use the user's interests and purchasing behavior, to recommend information and merchandise for users. With the expansion of e-commerce and the number of goods available online, customers require time to find the goods that they want to buy. Browsing of a large number of irrelevant information sources and product processes means that consumers experience information overload. Therefore, PRS was proposed (Modarresi, 2016). A personalized recommendation system is a high-level business intelligence platform that uses mass data mining to allow e-commerce website to provide a complete personalized decision support and information service for its customers (Xu et al., 2016). The recommendation system for a shopping website recommends the product for the customer and automatically completes the process of personalized selection of goods to meet the personalized needs of customers (Guan et al., 2005). The main algorithms for e-commerce recommendation system include association rule-based recommendation (Santos et al., 2018), content-based recommendation (Zheng et al., 2018) and collaborative filtering recommendation (Yang et al., 2017; Köhler et al., 2016; Xiao et al., 2018). The biggest advantage of personalized recommendation is that it collects user data and makes personalized recommendations for online users based on user characteristics, such as interests or preferences (Lee \& Brusilovsky, 2017; Gorgoglione et al., 2019). Personalized recommendation systems have many applications. A variety of online platforms and social networks that provide personalized services also require support from a referral system (Corbellini et al., 2015). In an increasingly competitive environment, personalized recommendation systems can retain customers and improve the service of e-commerce systems (Hsu et al., 2013; Cheikh-Ammar \& Barki, 2016; Hwangbo et al., 2018). On the other hand, a successful recommender system (RS) can bring great benefits using precise data mining analysis (Gao et al., 2018).

\section{METHODS}

\section{Research Framework}

This study developed a data mining framework for the proposed research strategy. We distributed a questionnaire regarding Taiwan mobile payment app users' behavior, added value, online purchasing, and consumer preferences. The proposed research framework is shown in Figure 1. We used an online survey to collect data, converted the findings into an Excel file and used the IBM SPSS Modeler to divide users through cluster analysis in the first phase. Finally, the Apriori algorithm (association rules) was used to find associations between variables. The generated association rules provided us with key factors that explore the characteristics of each user cluster. These rules can serve as references for developing business models.

\section{Questionnaire Design}

The questionnaire design is divided into six parts with 25 items. The first part includes seven demographic questions concerning gender, age, education, etc. The second part investigates mobile payment user behavior, including seven questions about mobile payment service, mobile payment device, purpose for using mobile payment, the physical/network of mobile payment technology 
purchases, bank of mobile payment use, etc. The third part investigates social media user behavior and includes four questions about which online community platform users use, motivational preferences of social networking sites, channels for participating in online communities, and biggest impression after participating in the online community. The fourth part investigates social network interaction behavior and includes four questions about the types of messages users share during social network interaction, whether users make comments or participate in discussions on social networks, which business models the social networks use, etc. The fifth part investigates social media/network marketing and include two questions about the kind of advertising/marketing techniques users find more attractive and which interactive mode is preferred in the social network. The last part investigates mobile payment behavior and includes four questions about which online malls users usually select when using mobile payment, what kinds of products users usually buy from online stores when using mobile payment, which issues concern users most when making these purchases, and at which location do users prefer to pick up or deliver products when using mobile payments. All questions are designed according to nominal and ordinal scales (not the Likert's scale). Most items are designed as multiple choice questions (the Appendix). For example: Which mobile payment service do you usually use?

(1) JKO pay (2) Taiwan pay (3) Pi mobile wallet (4) O'pay (5) GOMAJI Pay (6) friDay wallet (7) LINE Pay (8) Apple Pay (9) Samsung Pay (10)Android Pay (11) WeChat pay (12) Others

(Please list your three preference choices in order $/ /$ )

\section{Database Modeling - Relational Database Construct (E-R Model)}

A relational database construct organizes the detailed specifications of the entire data structure independently of database management technology, and defines the entire database (Codd, 1970). Often, conceptual architectures are rendered graphically, using the entity-relational model (E-R model). The E-R model was first proposed by Chen (1976) to describe database application content using a concept model, which is represented by entity, relationship, and data attributes, and mainly used as a communication tool for database designers and users. The E-R model is composed of entities of realworld objects about which we collect data and relationships existing between instances of those entity types. The E-R model, as shown in Figure 2, includes 15 entities, 7 relationships, and 90 attributes.

\section{Data Mining Tool - SPSS Modeler Implementation}

The IBM SPSS Modeler analytics software is a multi-functional big data analytics and data mining workbench that quickly and intuitively builds accurate predictive models and easily discovers patterns in structured and unstructured data. Modeler is a data mining and predictive analytics software that provides a variety of modeling methods that capture self-learning AI and statistical data from machines, each with a specific intensity best suited to specific types of problems. Modeler is a useful data analysis tool for business intelligence and analytics (Schuff et al., 2018). This study uses the SPSS Modeler to analyze data using K-means clustering, followed by the application of the Apriori algorithm to each cluster to analyze the association rules (Figure 3).

\section{DATA MINING APPROACH}

\section{Clustering Analysis}

The process of partitioning a large set of patterns into disjoint and homogeneous clusters is fundamental in knowledge acquisition. It is called Clustering in most studies and has been applied in various fields, including data mining, statistical data analysis, compression and vector quantization. The k-means is a very popular algorithm and is one of the best for implementing the clustering process. K-means clustering proceeds in the following order. First, the K numbers of observations are randomly selected 


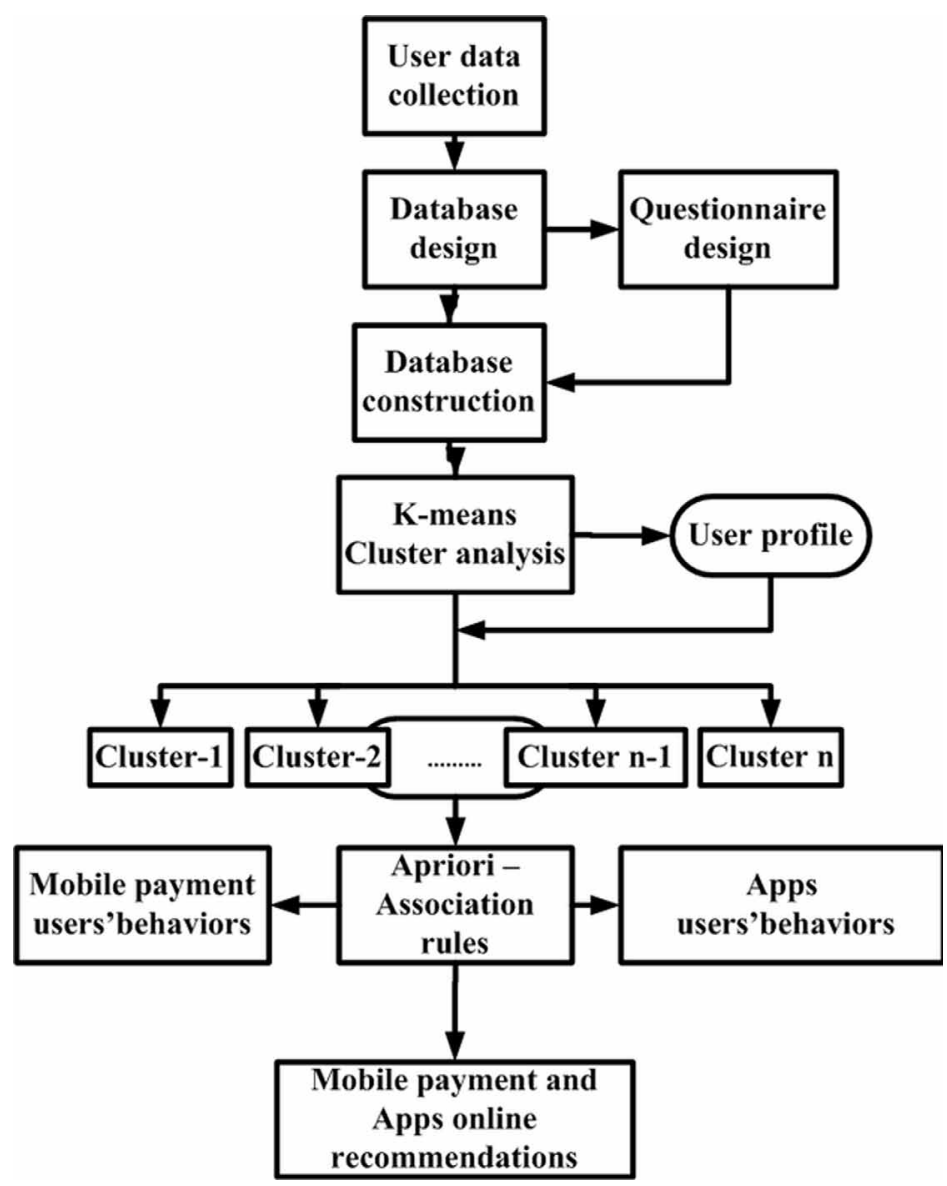

from all $\mathrm{N}$ number of observations according to the number of clusters, and these become centers of the initial clusters. Second, for each of the remaining N-K observations, the nearest cluster is found in terms of the Euclidean distance with respect to xi $=(x i 1, x i 2, \ldots ;$ xip, ., xiP $)$. After each observation is assigned to the nearest cluster, the center of the cluster is re-computed. Last, following the allocation of all observations, the Euclidean distance between each observation and the cluster's center point is calculated to confirm whether they have been allocated to the nearest cluster.

In addition, several studies have discussed implementation of the k-means algorithm for cluster analysis as a data mining approach (Ture et al., 2005). Cluster analysis, with its seemingly limitless power to produce groupings in any dataset, has all the trappings of a super-technique. However, the method produces clusters even in the absence of any natural structure in the data, and has no statistical basis to reject the null hypothesis that there are no natural groupings in the data. Application of cluster analysis, therefore, presupposes sound researcher judgment and responsible analysis and reporting. Balijepally et al. (2011) summarized the results of a reflective review of the application of cluster analysis in Information Systems (IS) research published in major IS outlets. Based on the analysis of 55 IS applications of cluster analysis, various deficiencies noticed in its use are discussed along with suggestions for future practice. In terms of referencing Balijepally et al. (2011), this study selects 14 variables as the variable set defines the structure of the dataset unraveled by the clustering process. Regarding to standardization of variables, this study eliminates differences in variance across 


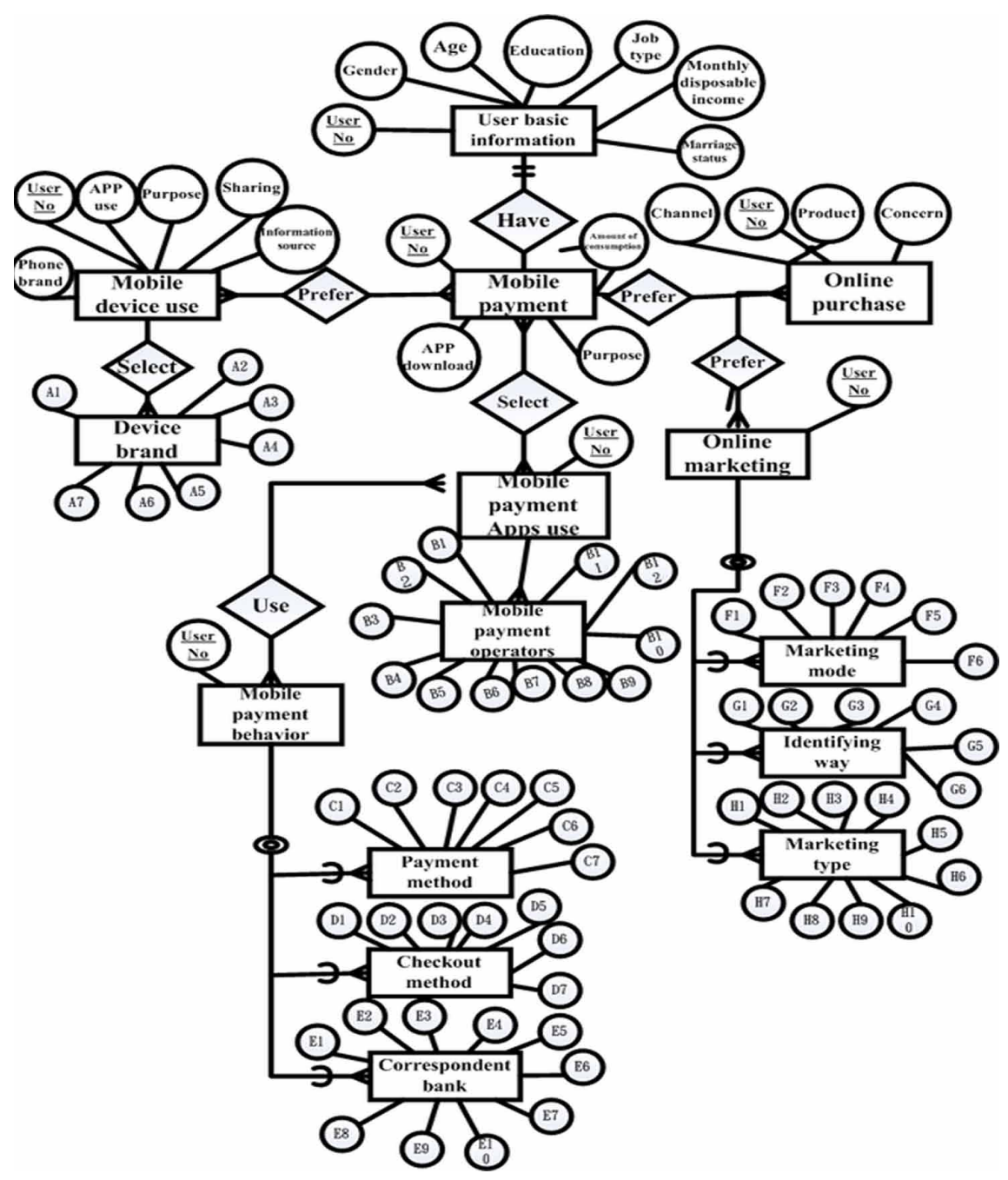

variables by considering a discernible effect on the cluster solution and adopts the cluster solution that exhibits higher validity. In these regards, this study uses the k-means as the approach and choses clustering variables according to Balijepally et al. (2011) suggestions on the application of cluster analysis in information systems research. The K-means clustering analysis results will demonstrate on the next section.

\section{Association Rules Analysis}

Discovering association rules is an important data mining problem (Agrawal et al., 1993), and there has been considerable research on using association rules for data mining problems. The association rules algorithm is mainly used to determine the relationships between items or features occurring synchronously in databases. For instance, during a trip to the shopping center, if the people who buy item $X$ also buy item $Y$, there exists a relationship between item $X$ and item $Y$. Such information is useful for decision makers. Therefore, the main purpose of implementing the association rules 


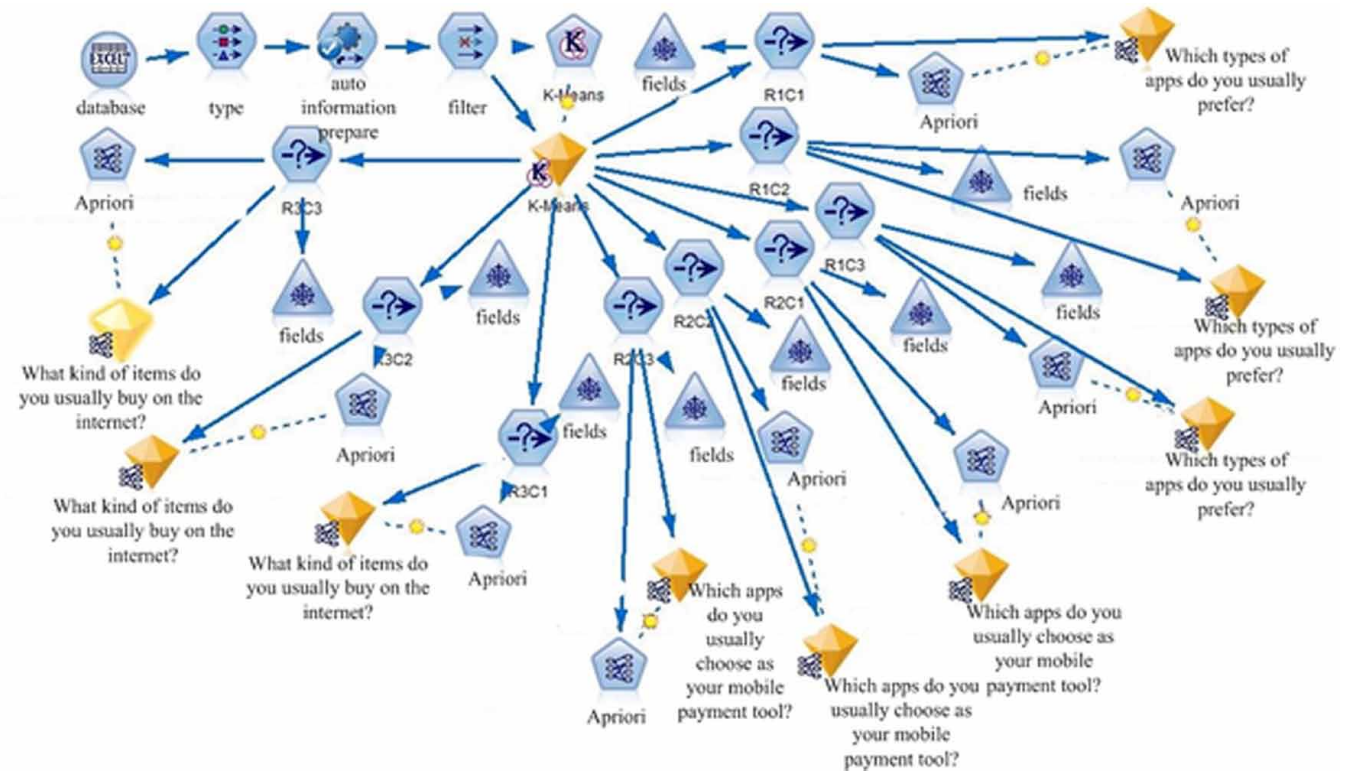

algorithm is to find synchronous relationships by analyzing random data and use these relationships as a reference for decision-making. The association rules are defined as follows (Wang et al., 2004):

Make $I=\left\{i_{1}, i_{2}, \ldots . i_{m}\right\}$ the item set, in which each item represents a specific literal. $D$ stands for a set of transactions in a database in which each transaction $T$ represents an item set such that $T \subseteq I$. That is, each item set $T$ is a non-empty sub-item set of $I$. The association rules are an implication of the form $X \rightarrow Y$, where $X \subset I, Y \subset I$ and $X \cap Y=\Phi$. The rule $X \rightarrow Y$ holds in the transaction set $D$ according to two measurement standards - support and confidence. Support (denoted as_Sup $(X, D)$ ) represents the rate of transactions in $D$ containing the item set $X$. Support is used to evaluate the statistical importance of $D$, and the higher its value, the more important the transaction set $D$ is. Therefore, the rule $X \rightarrow Y$ which has support $\operatorname{Sup}(X \cup Y, D)$ represents the rate of transactions in $D$ containing $X \cup Y$. Each rule $X \rightarrow Y$ also has another measuring standard called confidence (denoted as $\operatorname{Conf}(X \rightarrow Y)$ ), representing the rate of transactions in $D$ containing both $X$ and $Y$. That is, $\operatorname{Conf}(X \rightarrow Y)=\operatorname{Sup}(X \cap Y) / \operatorname{Sup}(X, D)$.

In this case, $\operatorname{Conf}(X \rightarrow Y)$ denotes if a transaction includes $X$, the chance this transaction also contains $Y$ is relatively high. The measure of confidence is then used to evaluate the level of confidence concerning the association rules $X \rightarrow Y$. Given a set of transactions, $D$, the problem of mining association rules is used to generate all transaction rules having certain levels of userspecified minimum support (called Min sup) and confidence (called Minconf). According to Agrawal et al. (1996), the problem of mining association rules can be broken down into two steps. The first step is to detect a large item set whose support is greater than Min sup, and the second step is to generate association rules, using the large item set. Such rules must satisfy the following two conditions:

1. $\operatorname{Sup}(X \cup Y, D) \geq \operatorname{Min} \sup$

2. $\operatorname{Conf}(X \rightarrow Y) \geq$ Minconf 
To explore association rules, many researchers use the Apriori algorithm (Agrawal et al. 1993). To reduce the possible biases incurred when using these measurement standards, the simplest way to judge the standard is to use the lift judgment. Lift is defined as: Lift $=$ Confidence $(X \rightarrow Y) /$ Sup $(Y)$ (Wang et al., 2004).

This study divides subjects into three groups using K-means analysis: cluster-1, Action early adopters group, cluster-2, Textured life taste group and cluster-3, 3C electronic product preference group. The E-R model is used to construct six major structures: "user profile", "mobile device preference", "Apps use behavior", "mobile payment behavior", " mobile payment service" and "recommendation mechanism". The association rules are used to determine the associations between and the significance of the consequent and antecedent for the generated patterns and rules. Rule-based recommendation is followed by association rule analysis of possible personalized recommendations. Figure 4 demonstrates the analysis model of the association rules.

\section{DATA MINING ANALYSIS RESULTS}

\section{K-Means Clustering Analysis Results}

K-means Clustering is implemented with 25 survey questions as input, while defining the number of clusters. Among these data, the distance between the centroid of each cluster is selected for clustering and then according to the chosen centroid, the data points having the minimum distance from the given cluster are assigned to that particular cluster. Cluster-1 includes 421 respondents; Cluster- 2 includes 407 respondents and Cluster-3 includes 280 respondents (Table 1).

\section{Cluster-1: Early Adopters Group}

This group is mainly composed of women under the age of 25 years old. They are mainly students who are in school and have a monthly disposable income of about TWD 10,000. They prefer social type apps (such as LINE, Facebook, WhatsApp, etc.) followed by music type (such as Spotify, KKBOX, Apple Music, etc.). The reason for downloading these types of apps is for professional functions; from the apps platform, they prefer to obtain and share information which is related to movie entertainment. LINE Pay is the mobile payment method used in daily life is, and recommendations from the operators that launched the action payment (such as Starbucks, High Speed Rail, Line, etc.) are the source of transaction information for mobile payment. This group prefers identity verification when using the mobile payment by inputting an alphanumeric password (such as a password, PIN code or authentication code). The reason affecting the use of mobile payment is that it is easy to use. The main items actually purchased from online stores are daily supplies (such as travel tickets, cleaning supplies, bathroom or kitchen utensils, etc.), followed by fashion items (such as clothing, accessories, boutiques, beauty care and shoe bags). The greatest concern about virtual consumption is the price of the commodity. The group of respondents dares to try new products.

\section{Cluster-2: Textured Life Taste Group}

This group is mainly composed of men aged $25 \sim 40$ years old. They mainly work in the technology industry in service and have a monthly disposable income of about TWD 20,001. They prefer food and drink apps (Uber Eats, Foodpanda, etc.), followed by shopping apps (Mobile Taobao, Momo shopping network, etc.). The reason for downloading this type of app to make purchase transactions on the apps platform. These users prefer to obtain and share health related information. The mobile payment method used in daily life is the JKO Pay, and the source of mobile payment transaction information is recommendations from businesses (such as in-store employee notifications or in-store DMs). The preferred method of identity verification is fingerprint scanning. The main items actually purchased from online stores are household items (such as kitchen utensils, storage, maternity goods, furniture, etc.), followed by fashion items (such as clothing, accessories, boutiques, beauty care, 


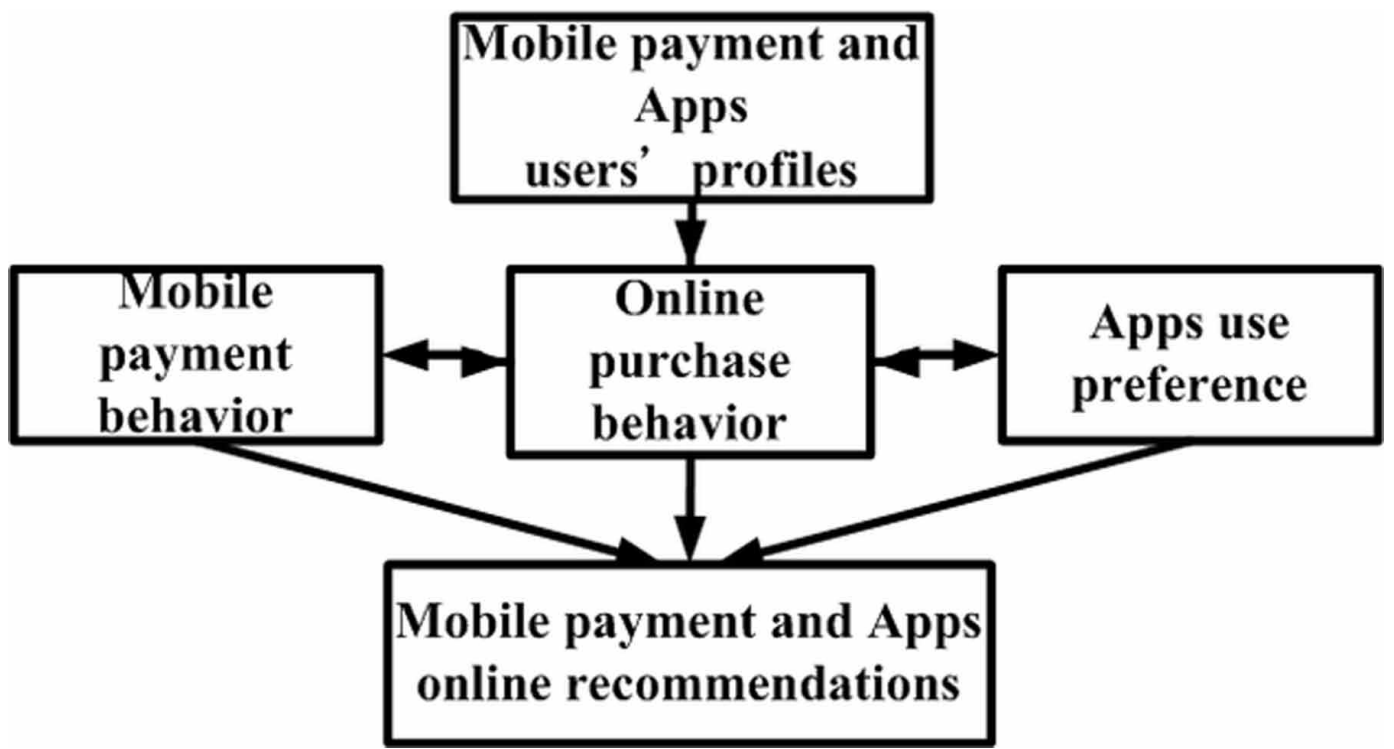

shoes, bags, etc.). The primary concern about virtual consumption is the price of goods. This group respondents values the taste and texture of life.

\section{Cluster-3: Electronic Product Preference Group}

This group is mainly composed of men aged between 25 years old and 40 years old. They mainly work in the technology or service industries and have a monthly disposable income of about TWD 20,001. They prefer social type (such as LINE, Facebook, WeChat or WhatsApp, etc.) apps. Their preferred shopping portal include Mobile Taobao, Momo shopping network, etc. They download apps for their professional functions from apps platforms. They prefer to obtain and share information related to new technology. JKO Pay is the main mobile payment method they use in daily life, and they receive recommendations from businesses to support mobile payment transactions (e.g., in-store employee notifications and in-store DMs). The preferred method of identity verification when using mobile payment is to input an alphanumeric password (such as a password, PIN code or authentication code, etc.), and the reason for choosing mobile payment is that it is easy to use. The main products purchased from online malls are leisure and transportation items (such as bicycle accessories, protective gear or sports fitness), followed by electronics (such as cameras, mobile phones, computer accessories, video games, etc.).

\section{Association Rules Analysis Results}

\section{Pattern 1: Associations of Apps, User Profiles and Mobile Payment}

Based on user's motivation to use a mobile payment, app types and app downloading preferences, we find out the types of mobile payment preferred by the users; by understanding the user's habits and behaviors, an operator can design and distribute exclusive consumption information to consumers. In this study, under the Minimum Antecedent Support of 2\% and Minimum Rule Confident of 40\%, five meaningful association rules are generated, as shown in Table 2 and Figure 5, and the lift values are all greater than 1.

It can be known from Rule 1 that users who prefer to use "other" types of apps mainly prefer "mobile phones". When downloading apps, "casual" is usually the main factor, and users like to obtain 
and share "popular things" using apps. Web discussion areas (including fan pages) is known to have a lot of information about apps. Rule 2 shows that users who prefer to use "social" type apps mainly use "mobile phones" and prefer to download apps with "professional features". Users like to obtain and share information about "movie entertainment" using apps, and they get information about apps mostly from "friends". Based on these rules, mobile payment, banking and brand merchants can design exclusive consumption information for users according to users' preference types. Moreover, messages containing information about users' preferred apps can be distributed through the appropriate channels. This method can satisfy the users' usage habits, enhance spending on apps, and meet the needs of apps users. Other association rules can also be derived from the information in the following table.

For the users of Cluster 2, in this study, under the conditions of a Minimum Antecedent Support of $2 \%$ and Minimum Rule Confidence of $40 \%$, five meaningful association rules are generated, and the lift values are all greater than 1 . For example, it can be known from Rule 1 that users who prefer to use "Gourmet \& Good Drinks" apps mainly use "mobile phones". When downloading apps, "professional features" are the main factor and these users enjoy searching for and sharing "shopping through apps". On the other hand, in regard to Cluster 3, under the conditions of a Minimum Antecedent Support of $2 \%$ and Minimum Rule Confidence of $40 \%$, five meaningful association rules are generated, and the lift values are all greater than 1. It can be known from Rule 1 that users who prefer to use "education" type apps mainly use "action tablets". "Professional features" is the main factor when downloading apps, and these users like to search absorb and share "health" category information through apps. The apps mainly provided information about "Family/Friends".

\section{Pattern 2: Associations of Mobile Payment Usage Behaviors}

Next we distinguish the users' actual use of the mobile payment tools based on users' reasons and the channel of information from the issuing bank to identify the users' preferred mobile payment tools; by understanding the reasons for use and the factors of consumers' mobile payment, banking and branding merchants can provide exclusive information to consumers. In the case of Cluster 1, this study generated 5 meaningful association rules, under the conditions of a Minimum Antecedent Support of 2\% and Minimum Rule Confidence of 40\%. The lift value is greater than 1 . Rule 2 shows that mobile payment users prefer to use "Apple Pay" as a payment tool. More frequent users of this tool bank at "China Trust". The channel for knowing information is "the recommendation of the operator who launched the action payment. The reason for use is "in case of emergency". With the following rules, mobile payment, banking, and brand merchants can choose the tools that users often use. The channels of communicating with the bank can be used to provide information and topics can be designed based on the reasons for attracting consumers to use them. In regard to Cluster 2, under the conditions of a Minimum Antecedent Support of $2 \%$ and Minimum Rule Confidence of $43 \%$, five meaningful association rules are generated, and the lift values are all greater than 1 . For example, Rule 3 indicates that mobile payment users use "LINE Pay" as a payment tool. Most users bank with "China Trust". The channel for the information is "recommendations from credit card operating banks." The reason for using mobile payment is to get "exclusive discounts". With the following rules, mobile payment, banking and brand merchants can choose users' frequently used tools and banks as information channels to promote messages, and design topics according to the reasons attracting consumers. In the case of Cluster 3, under the conditions of a Minimum Antecedent Support of 2\% and Minimum Rule Confident of $40 \%$, five meaningful association rules are generated, and the lift values are all greater than 1 . Rule 2 shows that mobile payment these mostly users use "Apple Pay" as a payment tool. The more frequent users bank with "Taipei Fubon Commercial Bank". The channel for receiving messages is "recommendations from friends and family". The reason for using mobile payment is the "advertising factor". The reason attracting users is "limited purchases". Based on these rules, mobile payment, banking and branding businesses can advertise through users' frequently used tools and banks, and design topics according to consumers' reasons for using mobile payment. 
Table 1. K-means cluster profiles and categories

\begin{tabular}{|c|c|c|c|}
\hline Data mining & \multicolumn{3}{|c|}{ K-Means Clustering } \\
\hline Cluster & Cluster-1 & Cluster-2 & Cluster-3 \\
\hline Cluster profiles & $\begin{array}{l}\text { Early adopters group } \\
\text { This group is mainly female, } \\
\text { willing to try and receive the } \\
\text { latest information, prefers } \\
\text { to use social type software, } \\
\text { and uses small payments to } \\
\text { purchase daily necessities. }\end{array}$ & $\begin{array}{l}\text { Textured life taste group } \\
\text { This group is mainly women, } \\
\text { has a stable income, likes } \\
\text { to explore food, often buys } \\
\text { household items through the } \\
\text { Internet, and creates a high- } \\
\text { quality life for themselves. }\end{array}$ & $\begin{array}{l}\text { Electronic product } \\
\text { preference group } \\
\text { This group is mainly } \\
\text { male, pays attention to the } \\
\text { professional functions of apps } \\
\text { and constantly searches for } \\
\text { scientific and technological } \\
\text { knowledge, and purchases } \\
\text { electronic products according } \\
\text { to permissible disposable } \\
\text { income. }\end{array}$ \\
\hline Number of sample & $421(37.9 \%)$ & $407(36.7 \%)$ & $280(25.4 \%)$ \\
\hline Gender & Female-dominated & Female-dominated & Male-dominated \\
\hline Age & Under 25 years old & $25-40$ years & 21-30 years \\
\hline Occupation & Student & Military and official & Technology \\
\hline $\begin{array}{l}\text { Monthly disposable } \\
\text { income }\end{array}$ & TWD 10,000 or less & TWD 20,001 or more & TWD 20,001 or more \\
\hline $\begin{array}{l}\text { Preference for using } \\
\text { APP type }\end{array}$ & $\begin{array}{l}\text { Social } \\
\text { Music }\end{array}$ & $\begin{array}{l}\text { Food } \\
\text { Shopping }\end{array}$ & $\begin{array}{l}\text { Social } \\
\text { Shopping }\end{array}$ \\
\hline $\begin{array}{l}\text { Reasons for } \\
\text { downloading Apps }\end{array}$ & Professional function & Shopping transaction & Professional function \\
\hline $\begin{array}{l}\text { Type of information } \\
\text { absorption and } \\
\text { sharing }\end{array}$ & Movie entertainment & Health & New technology \\
\hline $\begin{array}{l}\text { Mobile payment } \\
\text { method }\end{array}$ & LINE Pay & JKO Pay & JKO Pay \\
\hline $\begin{array}{l}\text { How they find } \\
\text { out about mobile } \\
\text { payment }\end{array}$ & $\begin{array}{l}\text { Credit card bank } \\
\text { recommendation }\end{array}$ & $\begin{array}{l}\text { Physical store } \\
\text { recommendation }\end{array}$ & $\begin{array}{l}\text { Physical store } \\
\text { recommendation }\end{array}$ \\
\hline $\begin{array}{l}\text { Preferred } \\
\text { verification method }\end{array}$ & Alphanumeric password & Alphanumeric password & Scanning finger prints \\
\hline $\begin{array}{l}\text { Purpose for using } \\
\text { mobile payment }\end{array}$ & Easy to use & Universal & Easy to use \\
\hline $\begin{array}{l}\text { Goods often } \\
\text { purchased online }\end{array}$ & $\begin{array}{l}\text { Daily goods } \\
\text { Popular goods }\end{array}$ & $\begin{array}{l}\text { Houseware } \\
\text { Popular goods }\end{array}$ & $\begin{array}{l}\text { Leisure and transportation } \\
\text { Electronics product }\end{array}$ \\
\hline $\begin{array}{l}\text { The biggest } \\
\text { concerned when } \\
\text { making purchases }\end{array}$ & Commodity price & After sales service & Commodity price \\
\hline
\end{tabular}

\section{Pattern 3: Associations of Mobile Payment and Online Purchase}

Based the shopping platform chosen by app users, the checkout method used, the verification method at the time of checkout, and the great concern about purchasing, users are differentiated according to motivation and willingness of the user to pay via app actions. We then investigate consumer behavior and the types of the users using virtual tools. When using apps, users use interactive technology to select products that are suitable for them, and then let the operators engage in online recommendation 
Figure 5. Association of Apps user profile and mobile payment (Cluster-1)

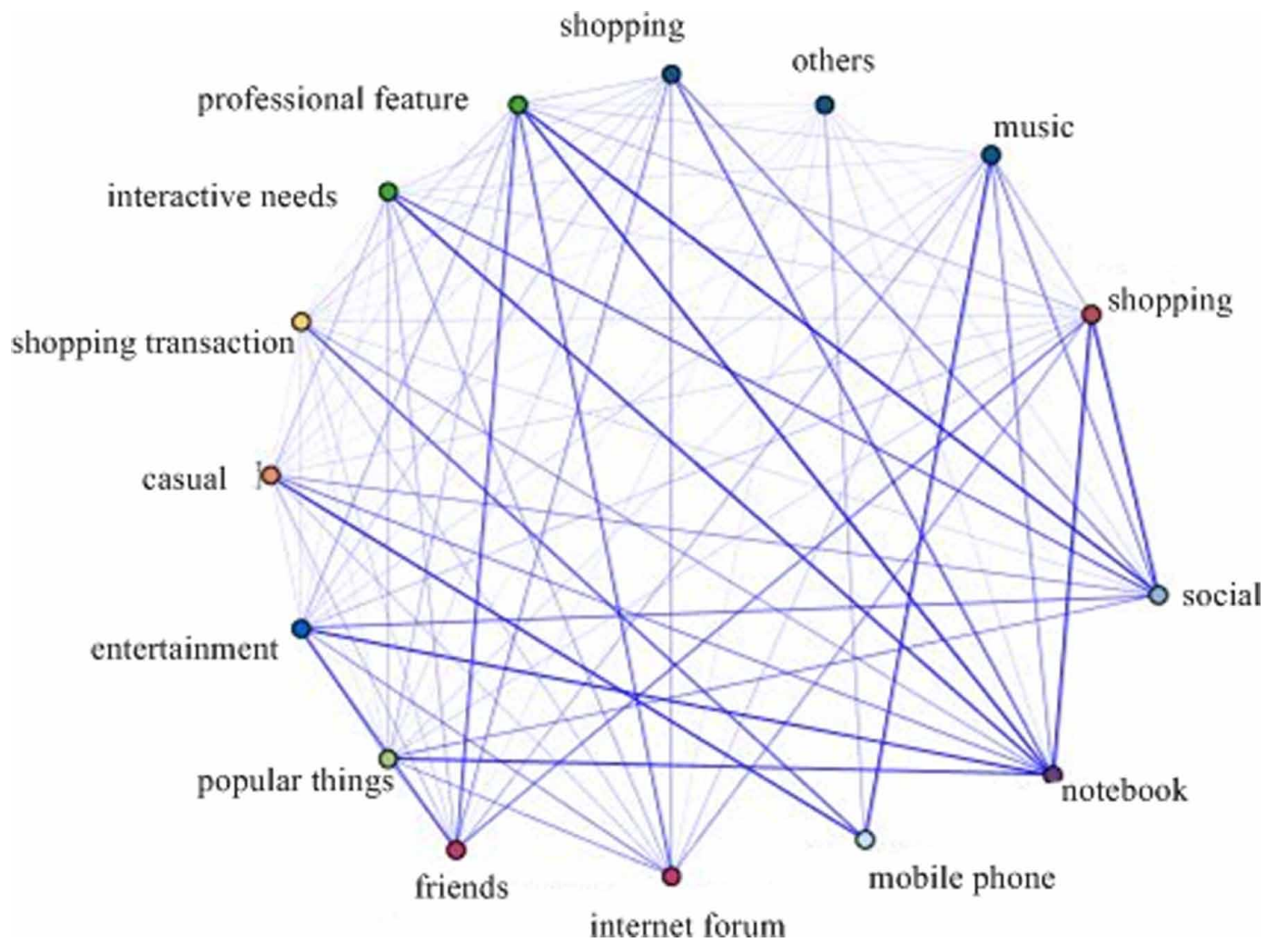

Table 2. Association of Apps user profile and mobile payment (Cluster-l)

\begin{tabular}{|c|c|c|c|c|c|c|c|c|}
\hline \multirow[b]{2}{*}{ Rule } & \multirow[b]{2}{*}{ Lift. } & \multirow[b]{2}{*}{ Sup. } & \multirow[b]{2}{*}{ Conf. } & \multirow{2}{*}{$\begin{array}{l}\text { Consequent } \\
\text { Apps type }\end{array}$} & \multicolumn{4}{|l|}{ Antecedent } \\
\hline & & & & & $\begin{array}{l}\text { Sharing/ } \\
\text { absorbing } \\
\text { information }\end{array}$ & $\begin{array}{l}\text { Source } \\
\text { of Apps } \\
\text { information }\end{array}$ & $\begin{array}{l}\text { Apps } \\
\text { download } \\
\text { reason }\end{array}$ & $\begin{array}{l}\text { How to use } \\
\text { Apps }\end{array}$ \\
\hline R1 & 7.32 & 2.37 & 40.00 & Others & Popular things & Internet forum & Leisure & Mobile phone \\
\hline R2 & 4.01 & 2.13 & 66.66 & Social & $\begin{array}{l}\text { Movie } \\
\text { entertainment }\end{array}$ & Friends & $\begin{array}{l}\text { Professional } \\
\text { feature }\end{array}$ & Mobile phone \\
\hline R3 & 2.81 & 2.13 & 55.55 & Shopping & $\begin{array}{l}\text { Movie } \\
\text { entertainment }\end{array}$ & Friends & $\begin{array}{l}\text { Shopping } \\
\text { transaction }\end{array}$ & $\begin{array}{l}\text { Notebook } \\
\text { computer }\end{array}$ \\
\hline R4 & 2.63 & 2.61 & 54.54 & Shopping & Popular things & Internet forum & $\begin{array}{l}\text { Interactive } \\
\text { needs }\end{array}$ & Mobile phone \\
\hline R5 & 2.18 & 2.37 & 40.00 & Music & Popular things & Friends & $\begin{array}{l}\text { Interactive } \\
\text { needs }\end{array}$ & Mobile phone \\
\hline
\end{tabular}


activities. In regard to Cluster 1, under the conditions of a Minimum Antecedent Support of 2\% and Minimum Rule Confidence of $40 \%$, five meaningful association rules are generated, and the lift values are all greater than 1 . Rule 1 shows most products purchased are "home supplies" purchased through the "PCHOME Online Shopping" using the "QR Code 2D barcode payment" on the channel. They prefer to use a "screen handwritten signature" for security when making purchases. The greatest concern when making purchases is, "the seller's reputation (word of mouth)". In the case of Cluster 2, Rule 4 indicates that users mainly purchase "daily life goods" through "GoHappy". Users of this type use the "QR Code 2D barcode payment" on the channel and prefer to use "fingerprint scanning" when making purchases. "Fingerprints" are used as a security verification at the time of transactions, and the biggest concern when making purchases is the "commodity price". Through the following rules, mobile payment, banking and brand business operators can integrate through the virtual channels used by users, and put advertisements or shopping information on the devices and platforms that consumers prefer to use. In regard to Cluster 3, under the conditions of a Minimum Antecedent Support of 2\% and Minimum Rule Confident of 50\%, five meaningful association rules are generated, and the lift values are all greater than 1 . Most of the products are "food \& beverage" products purchased through "PCHOME Online Shopping" using "NFC Payment" on the channel. Users are required to "enter letter symbols" during transactions for security verification. The greatest concern when making purchases is the "seller's attitude".

To sum up, among the types of products actually purchased, all three groups prefer "home products" and "daily goods department stores". Among them, Cluster-1 pays special attention to "popular trends" and also purchases "books and videos" and "3C electronics". Cluster-3 buys "food \& beverage" products. As for the choice of online shopping platform, all three groups prefer "PCHOM" and "GoHappy". In regard to the checkout method, all three groups consider "QR Codes" to be the most convenient payment method for mobile payment. For the verification method, all three groups expect different transaction verification methods to ensure the safety of purchases. Among the biggest concerns when making purchases, all three groups believe that "price" and "after-sales service" are essential when purchasing goods, and each group also pays attention to "seller's reputation", "attitude" and "safety of transactions" when purchasing goods.

\section{DISCUSSION}

\section{User Profiles and Apps Development Recommendations}

In terms of user profiles and apps development recommendations, this research uses the data exploration method to explore preferred app types, motivations and uses of app users by mobile payment apps users for the purpose of action payment development. This study aggregates and analyzes knowledge maps of three groups of users, enabling mobile payers, bankers, and brand traders to better understand the preferences of different clusters and thus assist in the development of mobile payments. In regard to app development, Cluster 1 users prefer "social", "shopping" and "music" apps. Cluster 2 users prefer "gourmet food \& drinks", "shopping", "maps \& navigation" and "social" apps. Cluster 3 users prefer "education", "business", "music" and "shopping" apps. The preferred type of app for all three clusters is "shopping" apps. It is recommended that mobile payment providers, bankers and brand traders can promote "shopping" when developing have new types of apps or have new activities and merchandise promotions. The type of app is the main method that can attract more users to use apps for payment actions. In regard to user preference integration, in terms of Cluster 1 users, the channels for using apps are mainly "mobile phones" and "notebooks", and the reasons for downloading apps are "leisure", "professional features", "shopping transactions" and "demand". In regard to Cluster 2 users, they prefer to use apps on "mobile phones" and the reasons for downloading apps are "professional features", "shopping transactions" and "travel demand". Cluster 3 prefers to use apps on "mobile phones" and "action tablets", and the reasons for downloading apps are "professional features" and 
"business needs". In regard to the sources of app messages, the users of all three clusters are informed by "Internet forum (including fan pages)" and "friends". Only the electronic technology group prefers the "family/relative" option. It is recommended that mobile payment, banking and brand merchants develop new types of apps and promote new activities and merchandise promotion. The preferred channels of "Internet forum (including fan pages)" and "friends" can be used to allow more action users to quickly grasp the information they want first hand. On the other hand, in regard to information shared and absorbed by users through apps, the three clusters differ in the information they prefer to obtain and share. It is recommended that action payment, banking and branding businesses can develop new types of Apps, new campaigns and product promotions, and can target the preferences of each group. Random delivery can be applied so that mobile payment users can keep track of their favorite information when making purchases (Figure 6).

According to Figure 6, mobile payment, banking and branding companies that aim to expand the scope of action payments can integrate the common parts of the three clusters in line with the preferences of all users and promote products via the preferred app type (shopping). For example, using YAHOO Shopping app, mobile payment, banking and branding businesses can use the user download information as a starting point for user discussion in the online discussion area. Discussions of experiences using apps can implicit promote the use of apps. However, different groups prefer to search for and share different kinds of information. Moreover, there are differences between the use of apps types and information channels. Different users can also be integrated through different devices. By finding the common habits and preferences of various groups, apps can be designed to attract more users, leading to more downloads and continued use.

\section{User Profiles and Mobile Payment Behavior Recommendations}

In terms of user profiles and mobile payment behavior recommendations, this study aggregates and analyzes the knowledge maps of the three groups, enabling action payment, banking and branding merchants to better understand the preferences of different clusters and thus assist in mobile payments, and interaction between banks, brand merchants and mobile payment users. In regard to mobile payment instrument preferences, Cluster 1 group prefers using "Apple Pay", "LINE Pay" and "JKO Pay". Cluster 2 and 3 prefer "GOMAJI Pay", "LINE Pay", "JKO Pay" and "Apple Pay", "LINE Pay", "Samsung Pay", "Android Pay" and "Taiwan Pay". The preferred type of all three cluster groups is "LINE Pay". Therefore, we recommend that mobile payment, banking and brand merchants aiming develop or promote new apps use "LINE Pay". Users pay more attention to mobile payments and payment transactions can also create topics in online discussion forums. On the other hand, in regard to why users use mobile payment to make purchases, this study found that if operators hope to develop mobile payment, issuing banks and brand businesses should include all consumer groups and integrate their consumption preferences. Thus, businesses can start providing mobile payment service to users. Before binding the payment method, let the consumer choose the appropriate feedback method. Both Cluster 1 and 2 prefer the "accumulation of shopping points". Mobile payment, banking and brand merchants can allow users to redeem goods through apps online or accumulate shopping points by making purchases. This practice not only allows users to enjoy point redemption but also to enjoy using mobile payment when shopping (Figure 7).

According to Figure 7, mobile payment, banking and brand merchants can clearly understand the preferences of various cluster groups using mobile payment, and can easily target each group via marketing. Cluster 1 and Cluster 2 prefer mobile payment, and use mobile payment for small purchases. In addition to enjoying the convenience of mobile payment, these users also want discounts. For example, LINE has also created a new choice for LINE Pay users in the field of mobile payment. LINE Pay supports the payment functions of many stores, from small stores to large department stores in the retail industry. If the mobile payment operators or vendor want to attract these two groups, this type of action payment model (small action payment combined with a stored value function) can be used to cause discussion and attract more users from these two groups. On the other hand, in regard 
Figure 6. Association map of user profile and Apps development recommendations

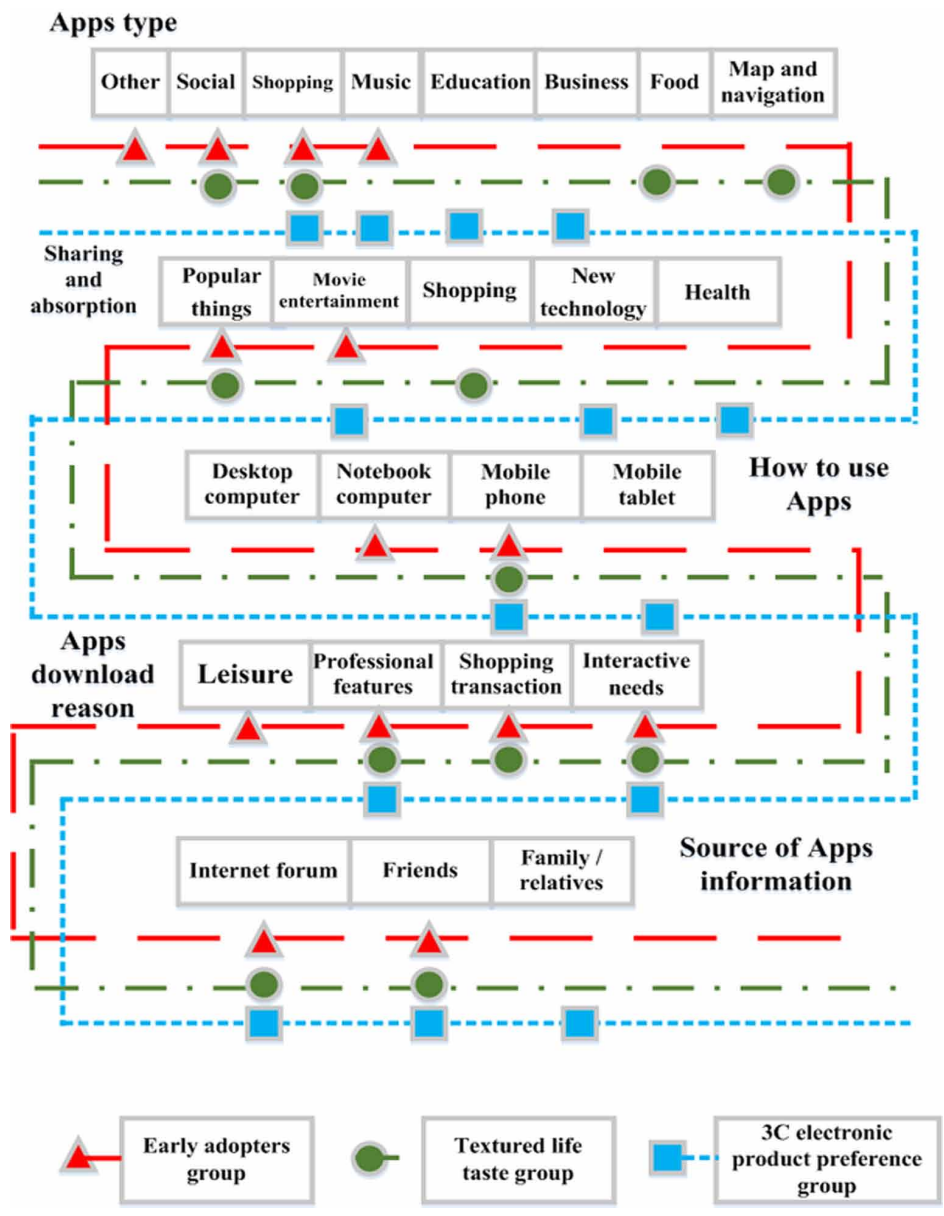

to Cluster 3, users of this group use more types of mobile payment apps because they like to try new technology, and the channel for receiving action payment messages is usually word-of-mouth recommendations from friends and relatives, and the reason for using mobile action payments to make purchases is to purchase a limited amount of goods. For example, PCHOME 24H shopping, the Pi wallet developed by its subsidiaries not only allow users to spend money on the platform and enjoy high discounts and discounts, but also users can also make small purchases in about 1,000 stores. If an action payment provider or vendor took similar actions to invest in app development, it would definitely generate great results and stimulate discussion in this group.

\section{Apps Mobile Payment and Online Recommendations}

In regard to online purchase preferences, Cluster 1 prefers to purchase "home goods", "daily goods department stores", "books and audio-visuals" and " electronic products"; cluster 2 group prefers to purchase "home goods", " daily goods" and "popular products"; and Cluster 3 group prefers to purchase "home supplies", "daily goods", "popular products" and "food \& beverages" online. The online shopping platforms preferred by these three cluster groups are "PCHOME Online Shopping" and "GoHappy"; the online shopping types are "home products" and "daily goods". It is recommended that operators or brands can recommend products/services online on the "PCHOME" 
platform. On the other hand, "GoHappy" is a major sales platform and can be used to promote "home products" and "daily goods" to the three groups. In regard to online purchase preferences, the preferred verification method of Cluster 1 when making purchases is "scanning fingerprints", "screen handwritten signatures" and "payment does not require any verification at the moment"; the preference of verification for Cluster 2 is "scanning fingerprints", "screen handwritten signatures" and "entering alphanumeric passwords"; Cluster 3 prefers "scanning fingerprints", "screen handwritten signatures", "entering alphanumeric passwords" and "payment does not need any verification". The preferred checkout method for all three groups is "QR Code 2D barcode payment"; the preferred verification method for online shopping checkout is "scanning fingerprints" and "screen handwritten signatures"; the biggest concerns when making purchases are "commodity price" and "after-sales service". Thus, we recommend that online shopping platforms and brand firms use the "QR Code 2D barcode" as the main online shopping checkout method and at the time of consumer checkout verification. "Scanning fingerprints" and "screen handwritten signatures" are the main verification methods that allow consumers to have a good shopping experience when shopping online and also allow users to protect their own consumer rights.

\section{PRACTICAL IMPLICATIONS}

Firstly, According to the statistics of the Taiwan Market Intelligence \& Consulting Institute (2018), $39.7 \%$ of smartphone users have used mobile payment to make purchases, and the near field communication (NFC) support rate of mobile phones has reached $61.4 \%$. Users' awareness of mobile payment rose from $84 \%$ last year to $91 \%$, and up to $77 \%$ of smartphone users have the willingness to start or continue to use mobile payments. The same survey also found that the two payment methods most commonly used by Taiwanese consumers are mainly cash and cards. However, the proportion of mobile payments has increased compared to last year. On the contrary, the proportion of cards has decreased slightly. In terms of Taiwanese consumption habits, when consumers use non-cash instruments other than cash, such as physical cards, mobile payments, and electronic tickets, noncash mainstream tools actually have partial substitution relationships it could even influence the consumer behavior of choosing to pay for games using cards in the future. This is the reason for the proportional growth and decline. However, as development enters the middle and late stages, the group that uses cash has the greatest development potential to become mobile payers. According to the above survey, Taiwan's current financial system is quite sound, and the usage rate of mobile payment has a steady growth trend. Mobile payment operators and manufacturers can simplify the operation interface of mobile payment to attract users. Mobile payment provides initial introductions, and various functions and usage methods. Online information can also be used in mobile payment to push more consumers to understand action payments. After users are familiar with it, operators can gradually add new functions (Fabisiak, 2018).

Secondly, the Taiwan Market Intelligence \& Consulting Institute (2018) conducted a survey of Taiwan mobile payment users. The results showed that $28.3 \%$ of users had deleted or disabled mobile payments, and the reasons for choosing to delete or disable service were lack of merchants providing the service (34.2\%), the offers were not ideal (31.7\%) and the payment was not used (22.5\%). Moreover, $31.3 \%$ of Android users deleted or disabled mobile payment service. In comparison, only $22.8 \%$ of iOS users deleted or disabled the service. At the age level, up to $45 \%$ of users aged 18 to 25 deleted or disabled the service. According to the above research, most online shopping in Taiwan is still based on desktop computers. If mobile payment companies and manufacturers want to strengthen their mobile payment marketing, the most important thing to improve is the operation interface. An easy-to-understand shopping interface would increase consumer desire to use action payments and meet the needs of 18- to 25-year-olds who are the most willing to make mobile payments. Mobile payment providers and vendors can consider the use of electronic tickets or bank account binding to overcome the problem of the inability of groups to use credit card binding action payments. Finally, 
Figure 7. Association map of mobile payment behavior recommendations

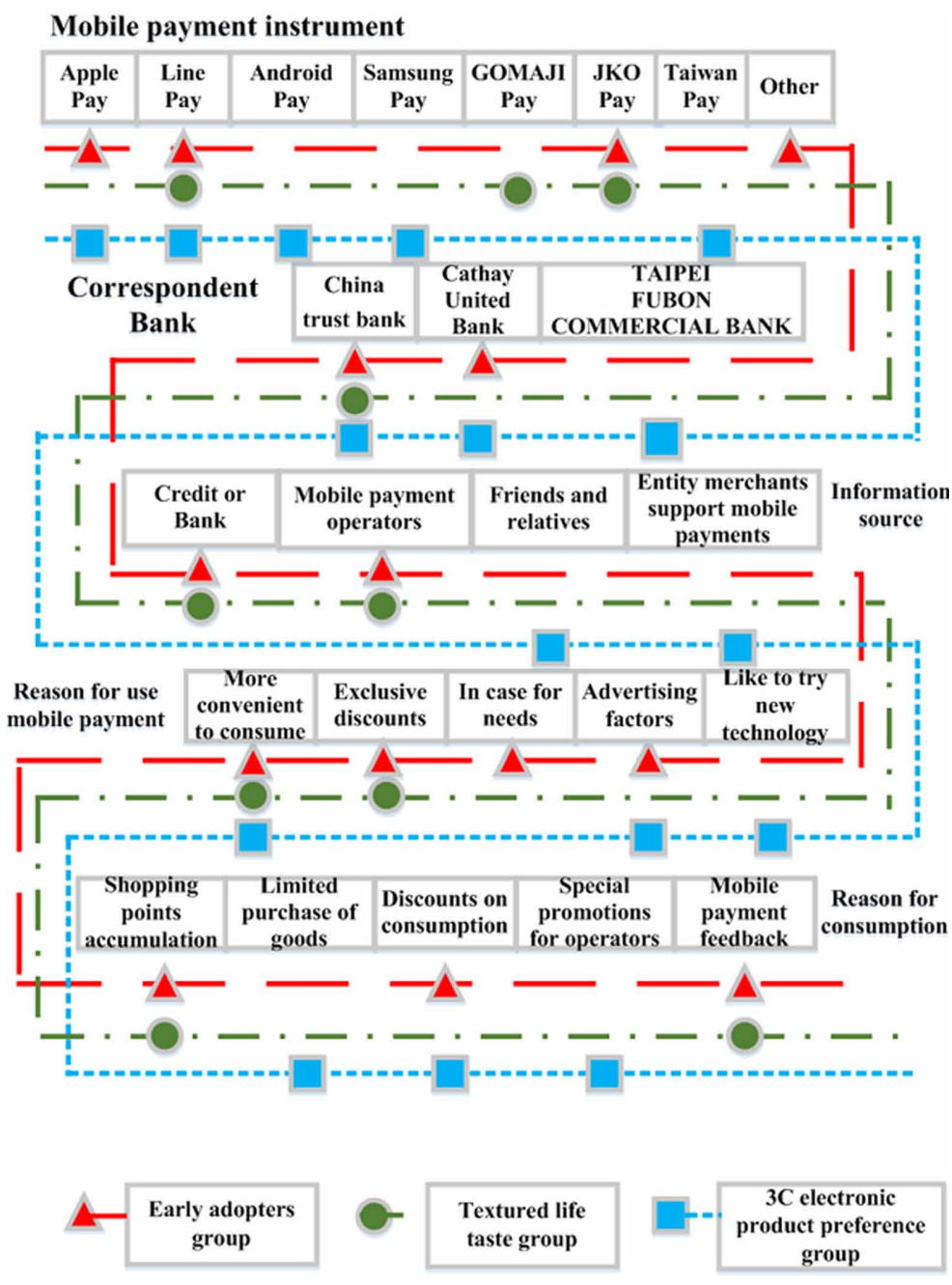

when it comes to consumers' concerns about consumer safety, compared with online shopping, the new generation of payment technology is much safer than traditional transaction payments. However, many consumers still have doubts about the security of mobile payment (Lu et al., 2011). Thus, operators and manufacturers can provide add-value service when the user uses the mobile payment action to spend large sums. The second method of verification is to reduce the user's doubts about the payment of the action.

\section{CONCLUSION}

In April 2018, the Deputy Governor of the Norwegian Central Bank stated that the country had actually entered a "cashless society". It is reported that $90 \%$ of the transfer transactions in Norway are now completed through non-cash electronic payments. Sweden was widely recognized as having entered a cashless society as early as 2015. Denmark began taking cash registers out of most stores in 2017. Only hospitals, pharmacies, post offices, etc., still have to accept cash payments as required by law. In areas with relatively high levels of development in Asia, such as China, Japan and South Korea, 
because credit cards and smart mobile devices are quite popular, it is easier for people to understand the convenience of mobile payment, and mobile payment has a certain degree of scientific credibility and popularity (Statista, 2019). In Taiwan, the popularization of mobile payment has taken a long time for each service mode. There are a certain number of users, and it is easy to form a complete mobile market structure based on a proper finance technology. In addition to the development of mobile payment apps mentioned above, this study collected user responses using a questionnaire distributed and collected in Taiwan. Then we processed the data models to produce a database. In these regards, this article highlight the major contributions as the followings: Firstly, in this study By using data mining techniques, clustering analysis and association rules, three clusters are illustrated according to varying characteristics, preferences, and behaviors as the early adopters group, textured life taste group, and electronic product preference group. Secondly, discussing various dimensions, we demonstrate the roles of new apps in mobile payment in the first place and then discuss how to produce better user experience with mobile applications as a new tool in terms of online recommendations. Thus, thirdly, this study shows that mobile payment not only can provide payment service but is also a critical mobile application platform for online business. Finally, we show that as users of mobile payment apps gain additional demand and consumption ability, providers can gradually put together mobile payment business models to enable future electronic commerce online recommendations.

\section{ACKNOWLEDGEMENT}

This research was funded by the Ministry of Science and Technology, Taiwan, Republic of China (MOST 109-2410-H-032-032-). 


\section{REFERENCES}

Agrawal, R., Imilienski, T., \& Swami, A. (1993). Mining Association Rules between Sets of Items in Large Databases. Proceedings of the 1993 ACM SIGMOD International Conference on Management of Data, 207216. doi: $10.1145 / 170035.170072$

Agrawal, R., \& Shafer, J. (1996). Parallel Mining of Association Rules. IEEE Transactions on Knowledge and Data Engineering, 8(6), 962-969. doi:10.1109/69.553164

Balijepally, V., Mangalaraj, G., \& Iyengar, K. (2011). Are We Wielding this Hammer Correctly? A Reflective Review of the Application of Cluster Analysis in Information Systems Research. Journal of the Association for Information Systems, 12(5), 375-413. doi:10.17705/1jais.00266

Bauer, J., \& Jannach, D. (2018). Optimal pricing in e-commerce based on sparse and noisy data. Decision Support Systems, 106(1), 53-63. doi:10.1016/j.dss.2017.12.002

Buettner, R. (2017). Predicting user behavior in electronic markets based on personality-mining in large online social networks. Electronic Markets, 27(2), 247-265. doi:10.1007/s12525-016-0228-z

Cao, X., Yu, L., Liu, Z., Gong, M., \& Adeel, L. (2018). Understanding mobile payment users' continuance intention: A trust transfer perspective. Internet Research, 28(3), 456-476. doi:10.1108/IntR-11-2016-0359

Cheikh-Ammar, M., \& Barki, H. (2016). The Influence of Social Presence, Social Exchange and Feedback Features on SNS Continuous Use: The Facebook Context. Journal of Organizational and End User Computing, 28(2), 33-52. doi:10.4018/JOEUC.2016040103

Chen, P. (1976). The Entity-Relationship Model - Toward a Unified View of Data. ACM Transactions on Database Systems, 1(1), 9-36. doi:10.1145/320434.320440

Chen, Y. L., Tang, K., Wu, C. C., \& Jheng, R. Y. (2014). Predicting the influence of users' posted information for eWOM advertising in social networks. Electronic Commerce Research and Applications, 13(3), 431-439. doi:10.1016/j.elerap.2014.10.001

Choi, D., \& Lee, Y. (2018). Eavesdropping of Magnetic Secure Transmission Signals and Its Security Implications for a Mobile Payment Protocol. IEEE Access : Practical Innovations, Open Solutions, 6(4), 42687-42701. doi:10.1109/ACCESS.2018.2859447

Corbellini, A., Mateos, C., Godoy, D., Zunino, A., \& Schiaffino, S. (2015). An architecture and platform for developing distributed recommendation algorithms on large-scale social networks. Journal of Information Science, 41(5), 686-704. doi:10.1177/0165551515588669

Dolliver, M. (2019). Ten Key Digital Trends for 2019. Available at: https://www.emarketer.com/content/tenkey-digital-trends-for-2019

Du, K. (2018). Complacency, capabilities, and institutional pressure: Understanding financial institutions' participation in the nascent mobile payments ecosystem. Electronic Markets, 28(2), 307-319. doi:10.1007/ s12525-017-0267-0

eMarketer. (2019). Forecasts - Mobile Apps User in 2018. Available at: https://www.emarketer.com/forecasts/ 584b26021403070290f93a2a/5851918a0626310a2c186a57

Euromonitor International Market Report. (2019). Euromonitor International Mobile Payment Market Report. Available at: https://www.euromonitor.com/solutions

Fabisiak, L. (2018). Web Service Usability Analysis Based on User Preferences. Journal of Organizational and End User Computing, 30(4), 1-13. doi:10.4018/JOEUC.2018100101

Fan, J., Shao, M., Li, Y., \& Huang, X. (2018). Understanding users' attitude toward mobile payment use: A comparative study between China and the USA. Industrial Management \& Data Systems, 118(4), 524-540. doi:10.1108/IMDS-06-2017-0268

Fang, Y. H. (2019). An app a day keeps a customer connected: Explicating loyalty to brands and branded applications through the lens of affordance and service-dominant logic. Information \& Management, 56(3), 377-391. doi:10.1016/j.im.2018.07.011 
Gao, M., Ling, B., Yang, L., Wen, J., Xiong, Q., \& Li, S. (2018). From similarity perspective: A robust collaborative filtering approach for service recommendations. Frontiers of Computer Science, 13(2), 231-246. doi:10.1007/s11704-017-6566-y

Gerpott, J., \& Meinert, P. (2017). Who signs up for NFC mobile payment services? Mobile network operator subscribers in Germany. Electronic Commerce Research and Applications, 23(1), 1-13. doi:10.1016/j. elerap.2017.03.002

Goldbach, T., Benlian, A., \& Buxmann, P. (2018). Differential effects of formal and self-control in mobile platform ecosystems: Multi-method findings on third-party developers' continuance intentions and application quality. Information \& Management, 55(2), 271-284. doi:10.1016/j.im.2017.07.003

Gorgoglione, M., Panniello, U., \& Tuzhilin, A. (2019). Recommendation strategies in personalization applications. Information \& Management, 56(6), 103143. doi:10.1016/j.im.2019.01.005

Guan, S. U., Chan, T. K., \& Zhu, F. (2005). Evolutionary intelligent agents for e-commerce: Generic preference detection with feature analysis. Electronic Commerce Research and Applications, 4(3), 377-394. doi:10.1016/j. elerap.2005.07.002

Hsu, C. L., Lin, C. C., \& Chiang, H. S. (2013). The effects of blogger recommendations on customers' online shopping intentions. Internet Research, 23(1), 69-88. doi:10.1108/10662241311295782

Huang, L. K. (2017). A Cultural Model of Online Banking Adoption: Long-Term Orientation Perspective. Journal of Organizational and End User Computing, 29(1), 1-22. doi:10.4018/JOEUC.2017010101

Huang, T. (2019). How does electricity business cross social media channels and conversational business? In terms of Taiwan's mobile payment trend. Available at: https://medium.com/8-interactive/

Hwangbo, H., Kim, Y. S., \& Cha, K. J. (2018). Recommendation system development for fashion retail e-commerce. Electronic Commerce Research and Applications, 28(1), 94-101. doi:10.1016/j.elerap.2018.01.012

Karim, A., Chang, V., \& Firdaus, A. (2020). Android Botnets: A Proof-of-Concept Using Hybrid Analysis Approach. Journal of Organizational and End User Computing, 32(3), 52-67. doi:10.4018/JOEUC.2020070105

Khan, A. N., Cao, X., \& Pitaf, A. H. (2019). Personality Traits as Predictor of M-Payment Systems: A SEMNeural Networks Approach. Journal of Organizational and End User Computing, 31(4), 89-110. doi:10.4018/ JOEUC.2019100105

Khatwani, G., \& Srivastava, P. R. (2018). Impact of Information Technology on Information Search Channel Selection for Consumers. Journal of Organizational and End User Computing, 30(3), 63-80. doi:10.4018/ JOEUC.2018070104

Köhler, S., Wöhner, T., \& Peter, R. (2016). The impact of consumer preferences on the accuracy of collaborative filtering recommender systems. Electronic Markets, 26(3), 369-379. doi:10.1007/s12525-016-0232-3

Kühl, N., Mühlthaler, M., \& Goutier, M. (2019). Supporting customer-oriented marketing with artificial intelligence: automatically quantifying customer needs from social media. Electronic Markets. 10.1007/s12525019-00351-0

Lee, D. H., \& Brusilovsky, P. (2017). Improving personalized recommendations using community membership information. Information Processing \& Management, 535(5), 1201-1214. doi:10.1016/j.ipm.2017.05.005

Lu, Y., Yang, S., Chau, Y. K., \& Cao, Y. (2011). Dynamics between the trust transfer process and intention to use mobile payment services: A cross-environment perspective. Information \& Management, 48(3), 393-403. doi:10.1016/j.im.2011.09.006

Magazine, M. (2019). Taiwan mobile payment survey 2017-2018. Available at: https://www.moneynet.com.tw/ article $/ 5877 / \% \mathrm{E} 5 \% 9 \mathrm{C} \% 96 \%$

Modarresi, K. (2016). Recommendation System Based on Complete Personalization. Procedia Computer Science, 80(4), 2190-2204. doi:10.1016/j.procs.2016.05.379

Newsletters, T. (2019). 2018 Global Mobile Payment Report. Available at: https://techcrunch.com/newsletter 
Pant, G., \& Pant, S. (2018). Visibility of corporate websites: The role of information prosociality. Decision Support Systems, 106(1), 119-129. doi:10.1016/j.dss.2017.12.006

Pauluzzo, R., \& Geretto, E. F. (2018). Validating the EUCS Model to Measure the Level of Satisfaction of Internet Users in Local Banks in Italy. Journal of Organizational and End User Computing, 30(1), 66-81. doi:10.4018/JOEUC.2018010104

Report, S. (2019). 2018 Global Mobile Payment Market Studies. Available at: https://www.statista.com/studiesand-reports/\#marketAnalysisMostPurchased

Santos, F. F., Domingues, M. A., Sundermann, C. V., Carvalho, V. O., \& Rezende, S. O. (2018). Latent association rule cluster based model to extract topics for classification and recommendation applications. Expert Systems with Applications, 112(1), 34-60. doi:10.1016/j.eswa.2018.06.021

Schuff, D., Corral, K., \& St. Louis, D. (2018). Enabling self-service BI: A methodology and a case study for a model management warehouse. Information Systems Frontiers, 20(2), 275-288. doi:10.1007/s10796-016-9722-2

Shahri, A., Hosseini, M., Phalp, K., Taylor, J., \& Ali, R. (2019). How to Engineer Gamification: The Consensus, the Best Practice and the Grey Areas. Journal of Organizational and End User Computing, 31(1), 39-60. doi:10.4018/JOEUC.2019010103

Son, J. (2017). The impact of initial experience and user attachment on application downloads: Informationseeking and -sharing applications. Internet Research, 27(2), 256-276. doi:10.1145/1518701.1518814

Sonawane, K. (2018). Mobile Payment Market- Global Opportunity analysis and industry forecast, $2016-2023$. Available at: https://www.alliedmarketresearch.com/mobile-payments-market

Sung, S. F., Lee, P. J., \& Hsieh, C. Y. (2020). Medication Use and the Risk of Newly Diagnosed Diabetes in Patients with Epilepsy: A Data Mining Application on a Healthcare Database. Journal of Organizational and End User Computing, 32(2), 93-109. doi:10.4018/JOEUC.2020040105

Taiwan Market Intelligence \& Consulting Institute. (2018). Action payment survey 1 - Nearly $40 \%$ of mobile phone users have used mobile payment. LINE Pay and Apple Pay have the highest recognition. Available at: https://mic.iii.org.tw/IndustryObservations_PressRelease02.aspx?sqno=486

Taiwan Market Intelligence \& Consulting Institute. (2019). 2018 Taiwan Mobile Payment Market Survey. Available at: https://mic.iii.org.tw/Industryobservation_MIC01views.aspx

Taiwan Semiconductor Research Institute. (2019). The Trend of Taiwan's Mobile payment Apps Development. Available at: https://www.tsri.org.tw/relation/media_main.jsp

Ture, M., Kurt, I., Turhan, K. A., \& Ozdamar, K. (2005). Comparing classification techniques for predicting essential hypertension. Expert Systems with Applications, 16(2), 379-384. doi:10.1016/j.eswa.2005.04.014

Wang, L., Luo, X., Yang, X., \& Qiao, Z. (2019). Easy come or easy go? Empirical evidence on switching behaviors in mobile payment applications. Information \& Management, 56(7), 103150. Advance online publication. doi:10.1016/j.im.2019.02.005

Wang, Y. F., Chuang, Y. L., Hsu, M. H., \& Keh, H. C. (2004). A personalized recommender system for the cosmetic business. Expert Systems with Applications, 26(1), 42-52. doi:10.1016/j.eswa.2003.10.001

Xiao, J., Wang, M., \& Jiang, B. (2018). A personalized recommendation system with combinational algorithm for online learning. Journal of Ambient Intelligence and Humanized Computing, 9(6), 667-677. doi:10.1007/ s12652-017-0466-8

Xu, W., Sun, J., Ma, J., \& Du, W. (2016). A personalized information recommendation system for R\&D project opportunity finding in big data contexts. Journal of Network and Computer Applications, 59(3), 362-369. doi:10.1016/j.jnca.2015.01.003

Yang, S., Korayem, M., AlJadda, K., Grainger, T., \& Natarajan, S. (2017). Combining content-based and collaborative filtering for job recommendation system: A cost-sensitive Statistical Relational Learning approach. Knowledge-Based Systems, 136(1), 37-45. doi:10.1016/j.knosys.2017.08.017

Yen, S. M., Lin, H. C., Chen, Y. C., Hung, J. J., \& Wu, J. M. (2014). PayStar: A denomination flexible micropayment scheme. Information Sciences, 259(1), 160-169. doi:10.1016/j.ins.2013.07.031 
Zheng, X., Luo, Y., Sun, L., Ding, X., \& Zhang, J. (2018). A novel social network hybrid recommender system based on hypergraph topologic structure. World Wide Web (Bussum), 21(4), 985-1013. doi:10.1007/s11280017-0494-5 


\section{APPENDIX A. THE QUESTIONNAIRE}

Part 1: Demographics

1. Gender:

2. Age:
Male $\square$ Female

$\square$ Under $25 \square 25$ years old (inclusive) 40 years old $\square 40$ years old and above

3. Education level:

$\square$ Middle school $\square$ High school $\square$ College $\square$ Graduate school degree

4. Occupation:

$\square$ Technology Industry $\square$ Financial industry $\square$ Service industry $\square$ Retail $\square$ Student $\square$ Others

5. Monthly disposable income:

(Freely disposable income after deducting fixed expenses, such as rent and loans)

$\square$ Below TWD 10,000 $\square$ TWD 10,000 20,000 $\square$ Over TWD 20,001

6. Marital status:

$\square$ Single $\square$ In relationship $\square$ Married

Part 2: Mobile payment behavior

7. The mobile phone brand you mainly use:
$\square$ Samsung $\square$ Apple
$\square$ SONY $\square$ Others

8. Where do you usually get the download information of the apps? (Multiple choice)

$\square$ Family/relatives $\square$ Friends $\square$ Classmates $\square$ Colleagues

$\square$ Internet discussion area

(Please list your two preference choices in order $L$ )

9. How do you usually use apps? (Multiple choice)

$\square$ Desktop computer $\square$ Laptop $\square$ Mobile phone $\square$ Tablet

(Please list your two preference choices in order $/$ )

10. What types of apps do you usually prefer to use? (Multiple choice)

$\square$ Education $\square$ Business $\square$ Food and drink $\square$ Social media $\square$ Shopping $\square$ Health and fitness $\square$ Tourism $\square$ Music $\square$ Maps and navigation $\square$ Sport $\square$ Weather $\square$ Others

(Please list your three preference choices in order $\angle /$ )

11. Why do you usually download apps? (Multiple choice)

$\square$ Professional function $\square$ Leisure and entertainment $\square$ Shopping transaction $\square$ Reputation $\square$

Smooth interface $\square$ User ratings $\square$ Social needs $\square$ Others

(Please list your three preference choices in order $/ /$ )

12. What kind of information do you prefer to share/absorb in the apps platform? (Multiple choice)

$\square$ Health $\square$ Workplace $\square$ Social news $\square$ Movies and TV $\square$ Social networks $\square$ Science and Technology $\square$ Politics $\square$ Gossips $\square$ Inspirational articles $\square$ Shopping information $\square$

Popular and fashions $\square$ Others

(Please list your three preference choices in order $\angle$ )

13. Why do you usually use mobile payment? (Multiple choice)

$\square$ More convenient for consumption $\square$ Exclusive discounts $\square$ In the case of emergency $\square$ Like to try new technologies $\square$ Advertising influence $\square$ Don't like to carry cash $\square$ Others 
(Please list your three preference choices in order $\angle /$ )

14. How much do you usually spend on a mobile payment in average?

$\square$ Below TWD $300 \square$ TWD 300 500 $\square$ TWD 500 1,000 $\square$ Over TWD1,000

15. Which mobile payment service do you usually use? (Multiple choice)

$\square$ JKO pay $\square$ Taiwan pay $\square$ Pi mobile wallet $\square$ O'pay $\square$ GOMAJI Pay $\square$ friDay wallet $\square$

LINE Pay $\square$ Apple Pay $\square$ Samsung Pay $\square$ Android Pay $\square$ WeChat pay $\square$ Others

(Please list your three preference choices in order $\angle$ )

16. Which banks do you use for mobile payment? (Multiple choice)

$\square$ China Trust Bank $\square$ E.SUN Bank $\square$ Taishin International Bank $\square$ Shin Kong Bank $\square$ Fubon Bank $\square$ Cathay United Bank $\square$ Union bank of Taiwan $\square$ Standard Chartered $\square$ Hua Nan Bank $\square$ Others

(Please list your three preference choices in order $\angle$ )

17. What mobile payment technologies have you used in physical or online stores to check out and get goods? (Multiple choice)

$\square$ QR Code payment $\square$ NFC: near field communication sensor payment $\square$ Sonic transmission payment $\square$ Multi-dimensional barcode scanning payment $\square$ Robot financial management $\square$ Mobile game credit payment $\square$ Others

(Please list your three preference choices in order $\angle /$ )

18. Through which channels do you usually know the source of mobile payment transaction information? (Multiple choice)

$\square$ Recommended by physical merchants that support mobile payment $\square$ Recommendations from companies who launched their own mobile payment $\square$ Credit card or banker's recommendation $\square$ User recommendations from the social networks $\square$ Recommended by relatives or friends $\square$ News media $\square$ My own experience

(Please list your three preference choices in order $L$ )

Part 3: Social media/ networking recommendations

19. Which physical stores do you usually choose to pay for goods? (Multiple choice)

$\square$ Restaurant $\square$ Convenience store $\square$ Supermarket $\square$ Department store $\square$ Pharmacy/Cosmetics $\square$ Apparel $\square$ 3C electrical appliances $\square$ Communication product $\square$ Entertainment $\square$ Others

(Please list your three preference choices in order $/ /$ )

20. When choosing mobile payment, which discounts are the most attractive ways for you to spend? (Multiple choice)

$\square$ Can enjoy high consumption discounts $\square$ Mobile payment reward activities $\square$ Accumulation of shopping points $\square$ Operator's special festival promotions $\square$ Limited product purchase $\square$ Card-issuing bank promotions

(Please list your three preference choices in order $L /$ )

21. When you use the service during checkout and payment, if you add which of the following identity verification methods, you can spend more at ease? (Multiple choice)

$\square$ No verification is required at the moment of payment $\square$ Enter alphanumeric password On-screen handwritten signature $\square$ Sliding graphic password $\square$ Scan finger fingerprint $\square$ Scan the iris of the eye $\square$ Facial recognition $\square$ Others

(Please list your three preference choices in order $\angle$ )

22. What are the (possible) main considerations that will affect your use of mobile payment? (Multiple choice)

$\square$ Universality $\square$ Good or easy to use $\square$ Consumption habits $\square$ Safety $\square$ Purchase item $\square$ Have a discount $\square$ Does the phone function support $\square$ Does the bank support $\square$ Convenience of trading platform $\square$ Others 
(Please list your three preference choices in order $\angle$ )

Section 6: Online shopping consumption behavior and habits of apps

23. Which apps online shopping malls do you usually choose to buy? (Multiple choice)

$\square$ PCHOME $\square$ GoHappy $\square$ momo mall $\square$ udn buy $\square$ ET mall $\square$ Yahoo $\square$ U-mall $\square$ PayEasy $\square$ ibon mart $\square$ Others

(Please list your three preference choices in order $/ /$ )

24. What kind of products do you actually purchase on the online store? (Multiple choice)

$\square$ Popular supplies $\square$ Lifestyle goods $\square$ 3C electrical appliances $\square$ Books, audio and video $\square$ Food and beverage $\square$ Homewares $\square$ Home appliances $\square$ Leisure transportation $\square$ Others

(Please list your three preference choices in order $/ /$ )

25. What do you care about most when shopping in online shopping malls? (Multiple choice)

$\square$ After-sales service $\square$ On time delivery $\square$ Commodity price $\square$ The seller's reputation (Wordof-mouth) $\square$ the seller's service quality $\square$ Seller's efficiency $\square$ Product quality $\square$ Security and reliability of transactions $\square$ Personal information confidential $\square$ Others

(Please list your three preference choices in order $\angle$ )

Shu-Hsien Liao $(P h D)$ is a professor in the Department of Management Sciences, Business and Management College, Tamkang University, Taiwan, Republic of China. He received the Ph.D. degree in Operational Research/ System Group of Business School, University of Warwick, U.K. His publications have appeared in the Decision Support Systems, European Journal of Operational Research, International Journal of Production Economics, Annals of Operations Research, Journal of the Operational Research Society, RAIRO - Operations Research, Information Sciences, Information processing \& management, Applied Intelligence, Applied Artificial Intelligence, IEEE Transactions on Systems, Man, and Cybernetics - Part C: Applications and Reviews, Journal of Information Science, Soft Computing, International Journal of Data Warehousing and Mining, International Journal of Computer Integrated Manufacturing, Journal of Experimental \& Theoretical Artificial Intelligence, Expert Systems With Applications, International Arab Journal of Information Technology, Industrial Marketing Management, The International Journal of Human Resource Management, International Journal of Contemporary Hospitality Management, Technovation, Knowledge Management Research \& Practice, Total Quality Management \& Business Excellence, Journal of technology transfer, Leadership and organizational development journal, International Journal of Services Technology and Management, International Journal of Web based communities, International Journal of Continuing Engineering Education and Life-Long Learning, Government Information Quarterly, Asia Pacific Management Review, Business Process Management Journal and Asia Pacific Journal of Marketing and Logistics. His current research interests are in Decision theory, Marketing, Technology management, Information management, Innovation management, Knowledge management, Decision support and knowledge systems, Electronic commerce, Data mining and business intelligence, FinTech, Supply (Demand) Chain Management and General management.

Chu-Hung Ho is an MBA of the Department of Management Sciences, Tamkang University, Taiwan, Republic of China. He is a manager of mobile payment operator in Taiwan. 